\title{
Autonomous Sheet Pile Driving Robots for Soil Stabilization
}

\section{Citation}

Melenbrink, Nathan, and Justin Werfel. Autonomous Sheet Pile Driving Robots for Soil Stabilization. In proceedings of the IEEE International Conference on Robotics and Automation (ICRA), Montreal, Canada, May 20-24, 2019.

\section{Permanent link}

http://nrs.harvard.edu/urn-3:HUL.InstRepos:38811567

\section{Terms of Use}

This article was downloaded from Harvard University's DASH repository, WARNING: No applicable access license found.

\section{Share Your Story}

The Harvard community has made this article openly available.

Please share how this access benefits you. Submit a story.

\section{Accessibility}




\title{
Autonomous Sheet Pile Driving Robots for Soil Stabilization
}

\author{
Nathan Melenbrink ${ }^{1 *, 2}$ and Justin Werfel ${ }^{1}$
}

\begin{abstract}
Soil stabilization is a fundamental component of nearly all construction projects, ranging from commercial construction to environmental restoration projects. Previous work in autonomous construction has generally not considered these essential stabilization and anchoring tasks. In this work we present Romu, an autonomous robot capable of building continuous linear structures by using a vibratory hammer to drive interlocking sheet piles into soil. We report on hardware parameters and their effects on pile driving performance, and demonstrate autonomous operation in both controlled and natural environments. Finally, we present simulations in which a small swarm of robots build with sheet piles in example terrains, or apply an alternate spray-based stabilizing agent, and quantify the ability of each intervention to mitigate hydraulic erosion.
\end{abstract}

\section{INTRODUCTION}

Pile driving, the task of sinking posts or similar building elements firmly into the ground, is a ubiquitous part of nearly every construction project. Piles provide foundation support, hold back soil during excavations, and in general increase stability where surface soil is not stable. In the construction industry, pile driving is an extremely energyintensive process carried out by skilled human workers using particularly heavy-duty machinery.

Sheet piles, interlocking linear building elements made from bent sheet material (typically steel) and driven vertically into the earth, are used in a variety of contexts. In urban construction, they form retaining walls allowing for prefoundation excavation. They provide slope stabilization in uneven terrain, used in contexts like highway construction. In ecological applications, they can aid with restoration of degraded environments in the form of check dams (walls anchored in the ground that mitigate erosion by slowing water velocity during storm surges) [1], as well as addressing problems associated with sea level rise such as erosion, inundation, and salinity intrusion by forming structures such as bulkheads, perpendicular groins, offshore breakwaters, and seawalls [2], [3].

Introducing automation into sheet pile driving could reduce costs and enhance safety for this critical construction task, as well as increase opportunity for interventions (e.g., for ecological protection or restoration) in environments where human presence is challenging. In this paper we present a design and prototype for a novel autonomous sheet pile driving robot, named Terramanus ferromurus or Romu

\footnotetext{
This work was supported by the Wyss Institute.

${ }^{1}$ Wyss Institute for Biologically Inspired Engineering, Harvard University, Cambridge, MA 02138, USA

${ }^{2}$ Institute for Computational Design and Construction, University of Stuttgart, Germany

*nathan.melenbrink@wyss. harvard. edu
}

(Fig. 1). The robot is designed to carry a payload of sheet piles into a target setting and drive them into the ground in sequence, producing a sturdy wall that could, e.g., reduce erosion from waves along a shoreline or flash floods in an arid environment. Romu uses a vibratory hammer to effectively insert sheet piles into granular media, and makes use of its own weight to help drive piles to greater depth without needing to carry excessive additional mass for that purpose. We characterize the effects of mechanical parameters on the depth and extraction force of driven piles, and demonstrate a pile-driving sequence in a natural environment.

We envision Romu operating in multi-robot teams to increase the speed and robustness of the pile-driving task in a large-scale setting. In simulation, we present a simple control algorithm based on following topographical contours, and evaluate its effect in an erosion scenario, showing that it significantly reduces soil displacement and overall loss.

\section{RELATED WORK}

\section{A. Robotics}

Ardiny et al. have conducted a recent survey of research on autonomous robots for construction automation [4]. While this survey includes a wide variety of construction tasks, most of these projects are limited to highly structured laboratory environments, and do not consider anchoring into the ground. Napp and colleagues have demonstrated construction of ramps conforming to unstructured terrains using amorphous materials [5], [6]. A few research projects have demonstrated novel construction tasks outside of controlled environments, such as the Digital Construction Platform presented by Keating et al. [7], and the 3-robot team for 3D printing large-scale ceramic structures demonstrated by Jokic et al. [8]. Hurkxkens et al. have developed robots for autonomous soil manipulation for landscaping scenarios, though they do not consider introducing manufactured building materials [9]. Beardsley et al. have demonstrated the BeachBot, an autonomous robot that rakes large-scale userspecified drawings into flat sand, using a fiducial system for localization [10].

\section{B. Construction}

Structures made from interlocking sheet piles are used for a variety of applications in the built environment (Fig. 2). Common methods for pile driving in commercial construction include drop hammers, jackhammers and vibratory hammers. The latter, which use eccentric weights to generate vibrations, are particularly effective with small-cross-section piles like sheet piling and with granular soils. More recent innovations include acoustic pile driving, which uses the 


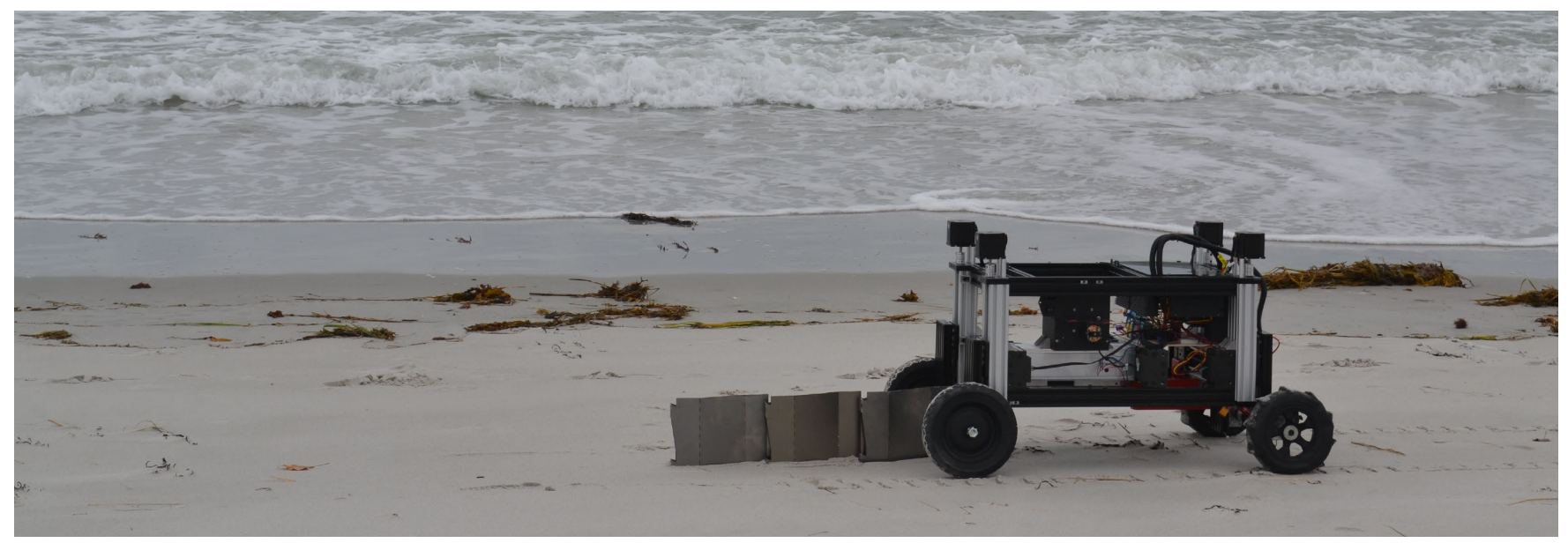

Fig. 1. Vision for Romu operating in a natural setting. Having installed the three piles it carries in one payload as the start of an erosion barrier, it heads for a supply cache to reload.

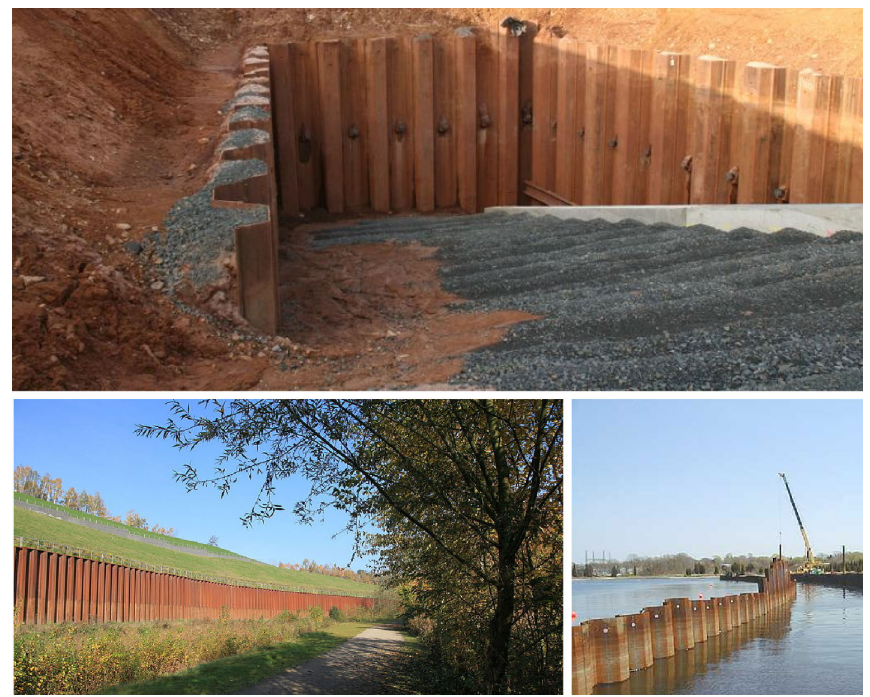

Fig. 2. Typical applications of sheet piling structures. In urban construction, they form retaining walls allowing for pre-foundation excavation (top) [14]. They provide slope stabilization in steep or uneven terrain (bottom left) [15]. In ecological applications, they are used for purposes like shoreline fortification (bottom right) [16]

changing natural frequency of a steel pile to facilitate driving into the ground. For construction in the United States, the Federal Highway Administration provides a manual with practical guidelines for hammer attributes and operating procedures for sheet pile driving. It notes that these guidelines are not universal and cautions against relying on them, suggesting that construction crews should instead primarily rely on empirical measurements of driving progress and alter their operation according to that on-site feedback [11].

While fully autonomous robots are not yet actively employed in the construction industry, semi-automated assistants are beginning to be used. SAM100 and MULE aid masons in bricklaying tasks [12]. The Silent Piler is a piledriving device that anchors into previously driven piles, leveraging downward force to help drive the current pile [13].

\section{Ecology}

A number of studies have looked at human interventions in the environment aimed at soil stabilization. These can be for purposes such as mitigating coastal erosion, stream bed erosion, or desertification. Guyassa et al. have reported on the utility of check dams (mostly built from stacked rocks or other materials found on-site) for reducing erosion and restoring vegetation in regions of Ethiopia prone to desertification [17]. Xu et al. have quantified the impact of the massive network of check dams in the Loess Plateau region of central China, which promotes groundwater recharge of arable land while mitigating deposition of sediments into the Yellow River [18]. While there are examples of robotics in environmental maintenance tasks such as hunting invasive species [19], [20], the automation of built interventions in the environment has remained largely speculative [21].

\section{HARDWARE}

A prototype robot, Romu, was developed as a proof of concept for these principles (Fig. 3). The robot is capable of carrying a payload of 3 sheet piles, locomoting to a new construction site, and installing the piles in sequence. The piles interlock to form a continuous wall (Fig. 4); by traveling between a construction site and a supply cache to reload, Romu could in principle construct a wall of arbitrary length.

To drive sheet piles, Romu uses a combination of vibratory excitation and its own body weight. In common construction practices, a heavy mass (a "bias weight") is suspended atop a driven sheet pile by machinery that must be heavy enough to counterbalance it, which represents an inefficient distribution of mass. Romu's morphology is unlike conventional piledriving equipment in that it employs its own body weight (in principle up to $100 \%$ ) towards downward force. Such weight distribution is made possible by the fact that its four wheels are mounted on vertical linear actuators (Fig. 3), which can retract to lower the robot's body and redistribute its weight from the ground onto the pile. 


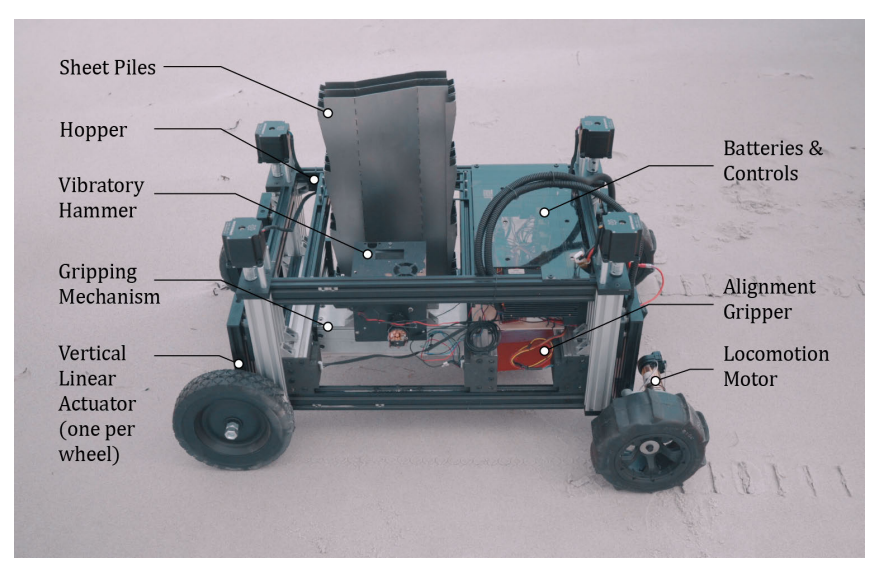

Fig. 3. A diagram of Romu, highlighting its salient features.

In addition to employing its own mass as a bias weight to press piles into the ground, Romu is also equipped with a vibratory hammer. Vibratory hammers use a pair of countermounted eccentric masses to convert angular momentum into vertical oscillations. The hardware parameters that govern pile driving performance are the eccentric weight, the rotation frequency of the eccentric weight, and the bias weight [11]. On large-scale construction projects, it is typical for pile-driving equipment to operate with eccentric moments exceeding $100 \mathrm{~m} \cdot \mathrm{kg}$, frequencies exceeding $1500 \mathrm{RPM}$, and bias weights in excess of 20 metric tons. Piles might need to be driven to depths of 30 or 40 meters, especially if they will be used in a permanent load-bearing capacity. While scaling down these parameters for a miniaturized operation is not straightforward, the small-scale sheet piles that are installed by Romu could serve as a self-sufficient structure for erosion control. Physical erosion barriers come in a wide variety of shapes and sizes. The structures built with the current custom piles might be best suited to low-impact coastal fortifications, or as check dams in areas prone to desertification.

The custom sheet piles (Fig. 4) are made from 16 ga. sheet steel, folded into an S-shaped profile that allows for piles to interlock. While interlocking is not strictly necessary for the applications of check dams or retaining walls, it is expected to improve the lateral load-bearing capacity of the structure. Each pile features notches spaced in $12 \mathrm{~cm}$ intervals, which provide a surface to receive the downward force of the vibratory hammer. To drive a pile, Romu grips the notches in its sides, activates the vibratory hammer, lowers its body $12 \mathrm{~cm}$ by retracting the four wheels' linear actuators, ungrips the pile and raises its body, and repeats. The length of drivable piles is thereby limited only by the penetrability of the soil and not by the robot's range of motion.

The angled cut of the notches in the piles is intended to facilitate the alignment of the gripping mechanism. Likewise, the gripping mechanism features angled pads made of pliable material to improve alignment and better grip the pile. While the robot body is mostly constructed of aluminum channel, the gripping mechanism is fashioned from custom-milled solid aluminum to minimize vibration damping, and the

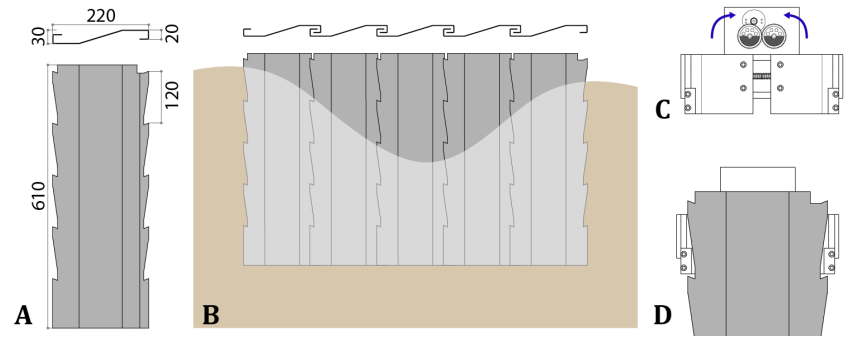

Fig. 4. (A) Dimensions of the custom sheet pile (mm). (B) Diagram of a check dam composed of 5 interlocking piles. (C) Counter-rotating eccentric weights mounted on the gripping mechanism. (D) Gripping mechanism closing into one of the pile's notches.

hammer surface that comes into contact with the pile is made of steel to prevent wear and tear.

Romu also features an alignment gripper (Figs. 3, 5) which is used to ensure the robot is aligned in the precise correct position prior to dropping a new pile from the hopper. This is particularly important for ensuring that piles will interlock, especially as locomotion encoding in sandy terrains is even less reliable than usual.

The robot's microcontroller allows for manual operation or an autonomous mode. All motors are powered by a single $14.8 \mathrm{~V}$ battery, with the exception of the vibratory hammer, which is powered by a separate $7.4 \mathrm{~V}$ battery.

The full sequence by which the robot extends an existing structure of interlocking sheet piles is described in Fig. 5 (see also Video 1). Romu is also able to begin new constructions simply by starting with Fig. 5 step (C) once it has determined an appropriate initial location.

\section{PERFormance}

In order to quantitatively characterize the robot's pile driving abilities, a testing arena was constructed. Natural variability in soil consistency presents a challenge for obtaining repeatable experimental results in natural settings. Therefore, the experiments for characterizing performance were conducted in an artificial sandbox filled with coarse sand commonly found at home improvement retailers. When a pile is driven into the sand, the sand becomes compacted in the vicinity of the pile. Such compaction would cause subsequent piles to be more difficult to drive. Therefore, after each trial the sandbox was inverted and shaken in order to restore the sand to an uncompacted state. Even in a fully uncompacted state, the resistance incurred when driving the pile increases with depth. The sandbox is $48 \mathrm{~cm}$ deep, though piles were never driven more than $40 \mathrm{~cm}$, to avoid edge effects near the bottom of the sandbox. While the robot was successfully demonstrated in an untethered state using a rechargeable battery, it was tethered for performance trials.

The performance measures considered were the depth to which a pile was driven and the force required to remove it afterwards. Three series of trials were conducted in order to evaluate the effects of changing eccentric weight, bias weight, and frequency of the vibratory hammer. The default values (held constant while varying other parameters) were 

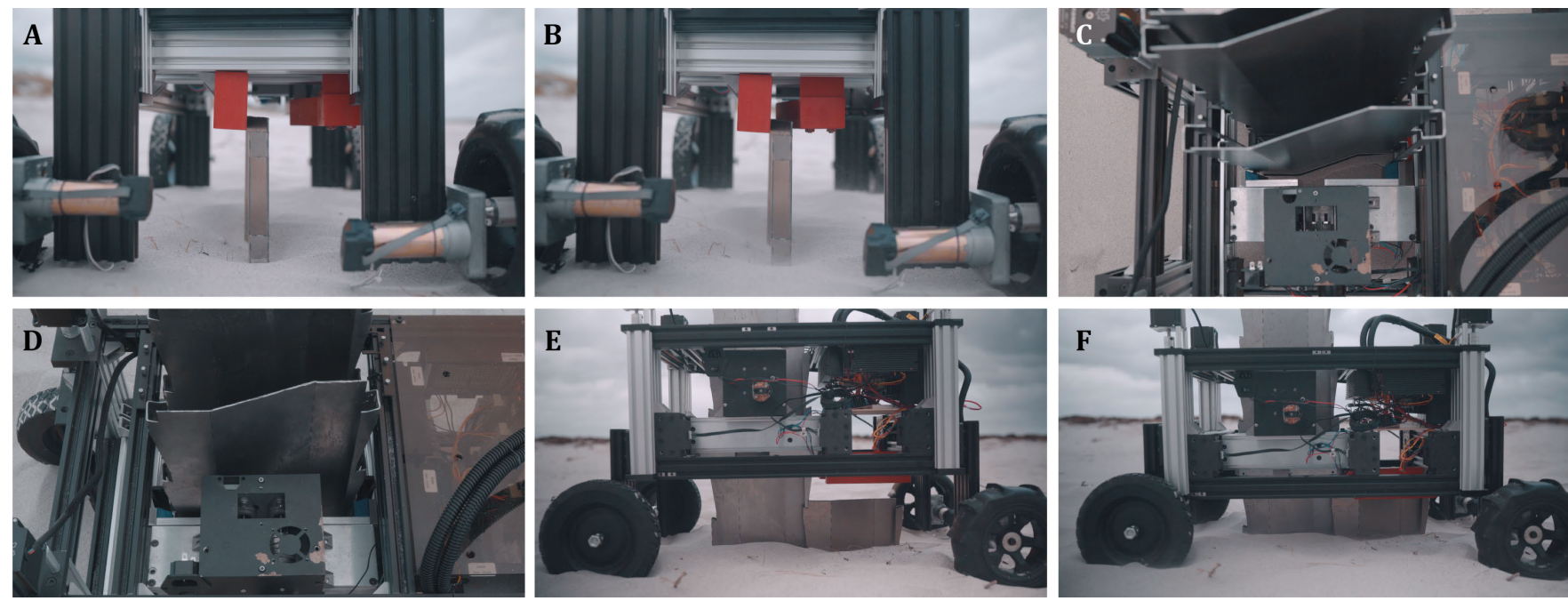

Fig. 5. The full sequence by which the robot extends an existing structure of interlocking sheet piles is as follows (see also Video 1): (A) The robot locomotes to a position such that its gripping mechanism is $\sim 20 \mathrm{~cm}$ in front of the last pile in the structure. (B) The alignment gripper (red) closes around the previous pile, aligning the robot more accurately with the existing construction, then releases. (C) The gripping mechanism retrieves a pile from the hopper and releases it, allowing it to fall to the surface of the ground while interlocking with the previous pile. (D) The linear actuators raise the robot such that its gripping mechanism is aligned with the next exposed notch in the pile. (E) The gripping mechanism closes, engaging with the notch in the pile. (F) The vibratory hammer is activated while the linear actuators lower the robot chassis $12 \mathrm{~cm}$, pressing the pile into the sand. The gripping mechanism then opens and the linear actuators raise the chassis $12 \mathrm{~cm}$, such that steps D-F can be repeated for as many notches as are on the pile. Once the pile is driven to the appropriate depth, the chassis raises in order to clear the top of the recently driven pile. Driving of the next pile begins with step A.

a bias weight of $24 \mathrm{~kg}$, hammer speed $2100 \mathrm{RPM}$, and eccentric weight $240 \mathrm{~g}$ (reduced to $120 \mathrm{~g}$ when varying bias weight to avoid hitting the bottom of the sandbox). Each trial was halted once the resistance of the sand could no longer be overcome by the robot, causing one or more of the wheels to lift off of the surface of the sand. The driven depth was then measured (Fig. 6). The results indicate that increasing any of the 3 parameters will result in approximately linear gains in the driven depth over this range. However, turning the hammer off (i.e., set to 0 RPM) results in drastically worse performance, demonstrating the effectiveness of the vibratory hammer compared to pressure alone. Measurements were also taken of the upward force required to extract the driven pile from the sandbox (Fig. 7). Increasing the values of eccentric weight, bias weight, and vibration frequency each resulted in approximately linear increases in the force required to extract the driven pile. Over this range of depths, we observed a roughly linear relationship between the driven depth of the piles $d$ and the force $F$ required to extract them: $F=(4.9 \mathrm{~N} / \mathrm{cm}) d-23 \mathrm{~N}$ (Fig. 8 ).

Using force plates, we found that the peak downward force exerted by the robot using the vibratory hammer can easily be twice its resting weight (Fig. 9).

In addition to these quantitative tests in a lab setting, we performed trial experiments with Romu in a natural environment, on a beach near Gloucester, Massachusetts (Fig. 5; Video 1). The sand there proved to be considerably more compacted than that in the lab sandbox, and with the default parameter values, the robot was able to drive piles only to a depth of 6-8 cm, approximately $1 / 4$ of the depth in the lab setting. (The piles shown at a greater depth in Fig. 1 were driven by hand.) Greater masses would allow driving to greater depths with a future version of the robot.

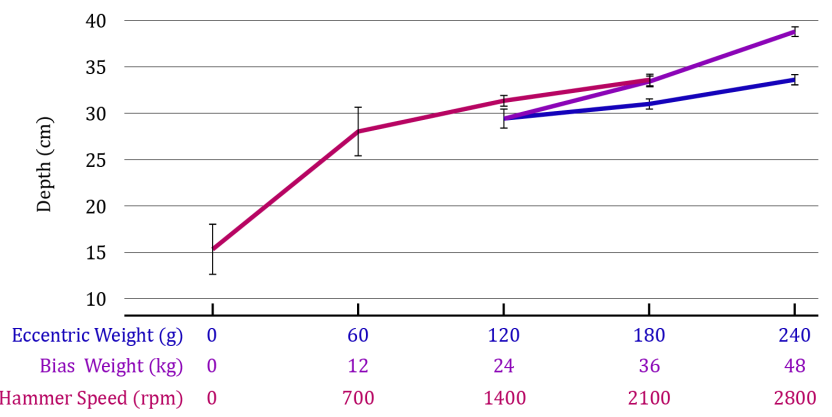

Fig. 6. The driven depth of the pile as a function of each of three parameters: eccentric weight, bias weight, and hammer frequency.

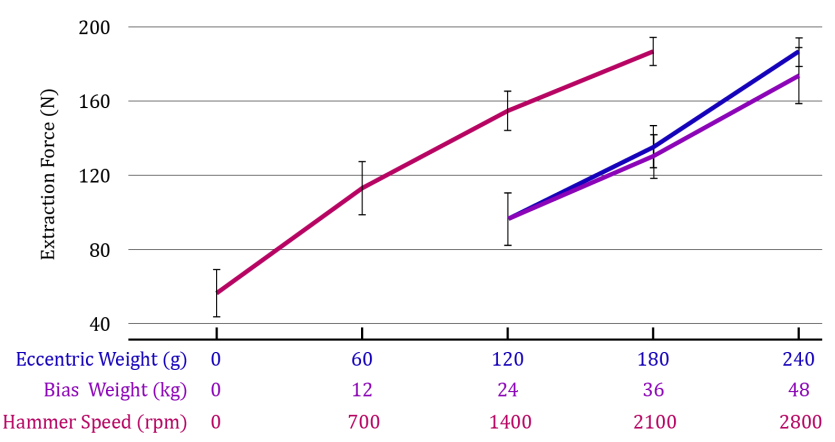

Fig. 7. The force required to extract a driven pile as a function of each of three parameters: eccentric weight, bias weight, and hammer frequency. 


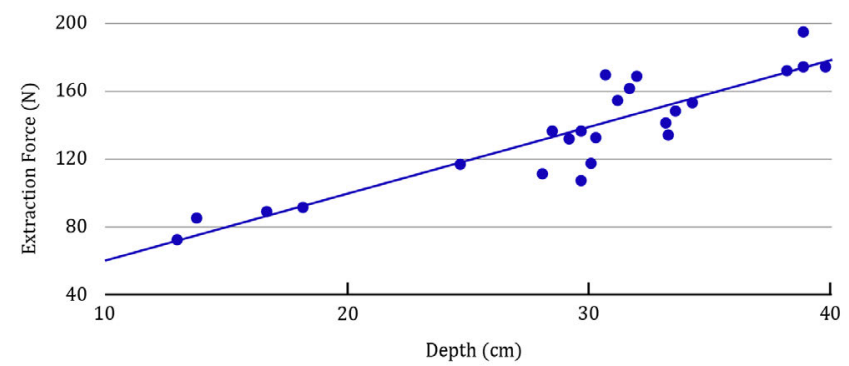

Fig. 8. The relationship between driven depth and the force required to extract the pile is roughly linear.

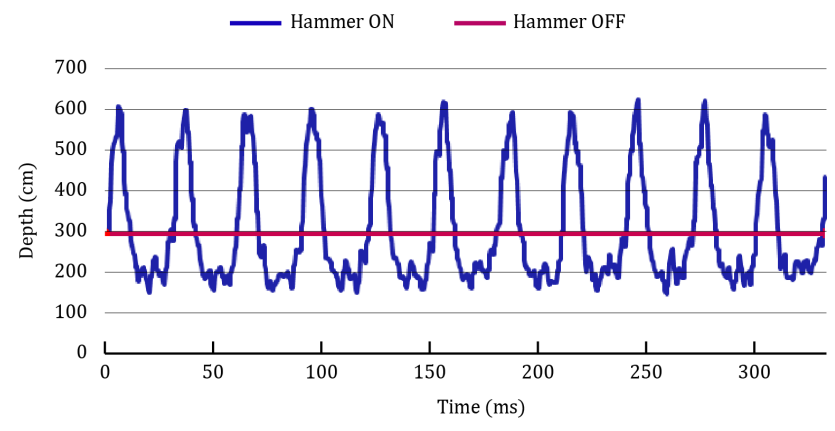

Fig. 9. Force plate readings, sampled at $2000 \mathrm{~Hz}$, showing the downward force exerted by the robot with and without the vibratory hammer (bias weight $30 \mathrm{~kg}$, eccentric weight $240 \mathrm{~g}$, hammer speed $2100 \mathrm{RPM}$ when on).

\section{Simulation}

Romu is intended to be operated as part of a decentralized collective. The kinds of environmental issues that it is suited to address (e.g., coastal erosion and desertification) are very large-scale and spatially diffuse, and would therefore benefit from the parallelism afforded by the swarm approach. Furthermore, the ability to autonomously perform coordinated building activity without requiring centralized control presents a considerable advantage, especially in large-scale operations in remote regions where reliable network communications are difficult to implement.

In many cases, a given watershed region would be better served by a multitude of small check dams distributed throughout the region than a single large structure at the bottom of the watershed [22]. With a considerably smaller form factor than conventional construction equipment, machinery at the scale of Romu could provide more targeted solutions with lesser site impact than currently available alternatives.

We hypothesize that a collective of distributed autonomous robots, each using only local information, would be able to make terrain interventions yielding a quantifiable reduction in erosion. We developed a custom simulation environment as a first exploration to test this hypothesis. Simulations take place in a $100 \mathrm{~m} \times 100 \mathrm{~m}$ terrain, generated at a $25 \%$ slope $\left(14^{\circ}\right)$ and randomized with Perlin noise (Fig. 10). In each simulation, 10 identical robots are initialized with random positions and orientations. When traversing the terrain, robots adjust their steering in order to maintain a constant elevation, thereby approximating contour lines. Robots install sheet piles where this means turning more sharply (radius of curvature $<14 \mathrm{~m}$ ); the motivation is that this puts dams in places where runoff will concentrate. When robots reach an edge of the terrain, they are removed and reintroduced at a new random position on the opposite edge.

After all robots have laid $10 \mathrm{~m}$ of piling (taken to be the payload capacity), the terrain is subjected to simulated hydraulic erosion, based on widely published algorithms used in the computer graphics community, notably variations on the method presented by Musgrave et al. [23]. This process begins by seeding "rain" to each $(\mathrm{x}, \mathrm{y})$ vertex $v$ of the 2.5-dimensional terrain mesh. For each iteration, a certain amount or "flow" of water $\Delta w_{u}$ is transported from each vertex $v$ to any of its 8 neighboring vertices $u$ that happen to be at a lower height $h$. This quantity is expressed as:

$$
\Delta w_{u}=\min \left(w_{v},\left(w_{v}+h_{v}\right)-\left(w_{u}+h_{u}\right)\right)
$$

Vertices on opposite sides of a sheet pile are not considered neighbors (we assume no water can flow through a check dam). For each vertex, all $\Delta w_{u}$ are summed and normalized, such that each neighboring vertex's flow $\Delta w_{u}$ is proportional to its angle of decline from vertex $v$. Each $\Delta w_{u}$ is subtracted from $w_{v}$ and added to $w_{u}$. Otherwise, in the absence of any outbound flow (i.e., the vertex is a local minimum), a fraction of the sediment suspended in the water at vertex $v$ is deposited. The sediment carrying capacity $c_{s}$ of the flow $\Delta w_{u}$ is the product of its magnitude and a carrying capacity constant $K_{c}$. If $\Delta w_{u}$ is carrying less than capacity, soil is eroded from the terrain and carried by the flow. If the flow carries more than capacity, it must deposit sediment to the terrain. Sediment levels at sites on the edges of the terrain are held constant to avoid edge effects. The above steps are applied to each vertex of the terrain, modeled as a mesh with a $500 \times 500$ resolution. Results on 3 different terrains (averaged over 5 trials each) are reported in Table I. "Sediment Lost" is the cumulative measure of all sediment that is transported off of the terrain due to hydraulic erosion, while "Sediment Displaced" is measured as the sum of the negative displacement of each vertex $f_{d}=\max \left(0, v-v^{\prime}\right)$, where $v$ is the initial height of the vertex and $v^{\prime}$ is the height of the vertex after the erosion routine.

Table I shows that this check dam intervention can retain $\sim 50 \%$ of the soil that would otherwise be washed away. A significant amount of sediment is still redistributed within the terrain, however, carried down from higher points to pile behind the dams.

In some applications, an alternate intervention may be preferred: e.g., using a less permanent material than steel to form a bio-scaffolding that degrades as vegetation is restored, or by spraying a liquid binding agent to increase soil cohesion in selected areas. Such interventions are commonly used to stabilize soil on gentler slopes, affecting a greater surface area but less capable of slowing runoff. We additionally simulated such an approach with hypothetical robots (dubbed Terramanus conferumino) carrying a spray 


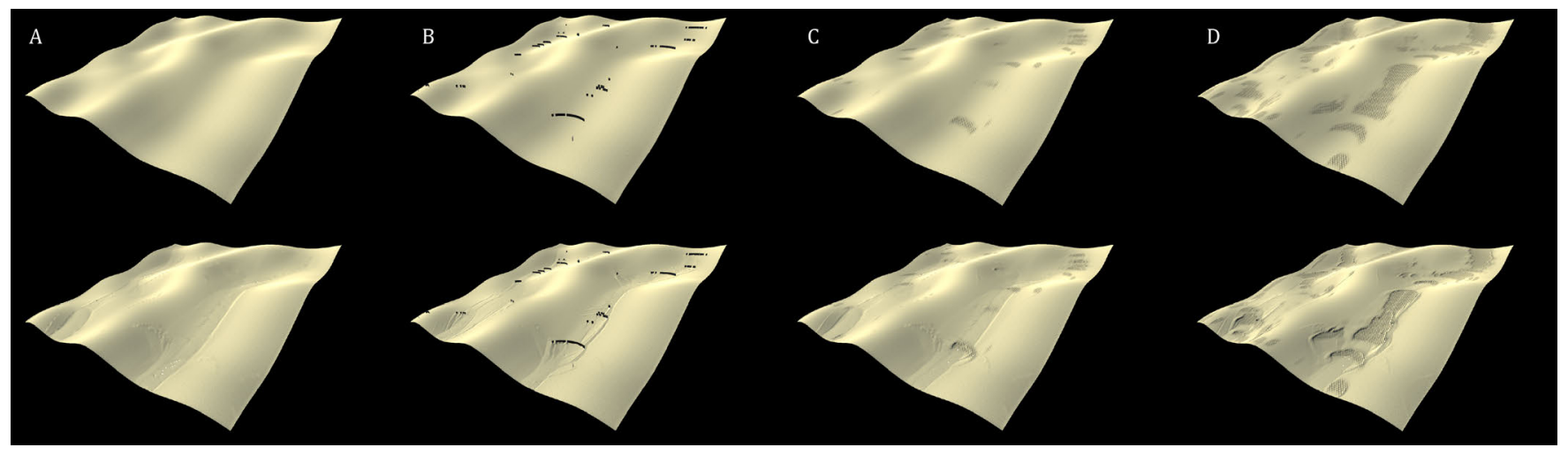

Fig. 10. A randomly generated terrain (Terrain A as reported in Table I), before and after erosion simulations, when subjected to 4 different treatments: (A) no intervention, (B) "Check Dams", where each robot's payload consists of 10m of interlocking steel piles as described in the previous section, (C) "Spray", where each robot's payload contains enough soil binding agent to cover 10m, and (D) "Spray $10 x$ ", where payloads are sufficient to cover $100 \mathrm{~m}$.

agent. Soil binding agents counter the process of erosion in a different way than rigid piles. Musgrave et al. present a soil softness constant $K_{s}$, which defines the rate at which soil will be subtracted from $v$ and converted to transportable sediment $s$, which is carried by $\Delta w_{u}$ :

$$
s_{u}^{\prime}=s_{u}+s_{v}+K_{s}\left(c_{s}-s_{v}\right)
$$

In our implementation, we replace the soil softness constant $K_{s}$ with variable softness $f_{v}=\max \left(0,1-B_{v}\right)$, where $B_{v}$ is the amount of binding agent deposited at vertex $v$; a vertex with a softness of 0 will not allow any subtraction of sediment.

Robots using this spray agent in place of metal check dams, each applying the spray again over a distance of $10 \mathrm{~m}$, can be expected to be less effective at reducing erosion (Table I). However, a potential advantage of a sprayed binding agent is that a quantity covering a larger area can reasonably be carried in a single payload. The last column in Table I shows that if robots carry enough spray to apply over a linear distance of $100 \mathrm{~m}$, soil displacement is reduced compared to the check dam intervention.

TABLE I

EFFECTS OF HYDRAULIC EROSION ON SEDIMENT $(m)$

\begin{tabular}{llllll}
\hline & Intervention: & None & Check Dams & Spray & 10x Spray \\
\hline A & Sed. Lost & 11.9 & $6.4 \pm 1.4$ & $11.0 \pm 0.6$ & $8.8 \pm 1.5$ \\
& Displaced & 50.9 & $42.1 \pm 1.0$ & $48.1 \pm 1.2$ & $38.7 \pm 1.9$ \\
\hline B & Sed. Lost & 6.7 & $3.8 \pm 0.6$ & $6.4 \pm 0.3$ & $4.9 \pm 1.0$ \\
& Displaced & 48.0 & $40.3 \pm 0.6$ & $44.6 \pm 0.3$ & $37.7 \pm 1.5$ \\
\hline C & Sed. Lost & 5.8 & $2.9 \pm 0.4$ & $5.5 \pm 0.4$ & $4.3 \pm 0.9$ \\
& Displaced & 51.5 & $42.1 \pm 1.2$ & $47.9 \pm 0.8$ & $39.0 \pm 2.3$ \\
\hline
\end{tabular}

\section{Discussion}

Research has only recently begun to indicate the tremendous potential of autonomous robots in the natural and built environments. While our research is interested specifically in geomorphological construction tasks that confer benefits to ecosystem services, other ecological interventions range from monitoring tasks to controlling the populations of invasive species. Broadly, these developments point to the need for a "machine ecology", a study of the relationships between custom purpose-built autonomous machines and the environment. (The vision of such an ecology inspires the taxonomic naming scheme of the robots presented in this paper.)

While Romu is able to consecutively drive piles in uncompacted sand, the sand found in natural environments is at least partially compacted and anisotropic, and in our pilot trials in such an environment we found the driving ability to be much more limited. In order to perform effectively in a natural environment, the eccentric and bias weights would need to be increased. However, the factors by which those parameters should be altered will vary as a function of the specific environment and application in which Romu 2.0 would operate. We therefore intend to work with ecologists to identify promising specific applications for which we can adjust the design parameters.

Historically, construction equipment has been designed according to ergonomic constraints for human operators. One advantage of autonomy is the ability to disregard these constraints and re-conceptualize the scale and scope of ecological construction tasks. For example, the ideal solution for some erosion prevention tasks might be a single Romulike robot at ten times the size of the current prototype, while another context might require a swarm of hundreds of robots at one-tenth the current size in order to adequately minimize sediment displacement.

We hope that this and further demonstrations of machine ecology will inspire ecologists and other environment professionals to conceptualize the maintenance and construction tasks that could be performed by swarms of task-specific autonomous robots.

\section{ACKNOWLEDGMENTS}

We thank Tom Blough, Stan Cotreau and Steve Sansone for assistance with fabrication; Achim Menges for advice and discussions; Stavros Calos, Charles Waldheim, Paul Kassabian and Giuliana Zelada-Tumialan for civil engineering advice; Charles Wolcott for site access for testing and filming; Amro Arida and Jiyoo Jye for help with filming. 


\section{REFERENCES}

[1] W. M. Linder, "Stabilization of stream beds with sheet piling and rock sills," in Proceedings of the Federal Interagency Sedimentation Conference, Subcommittee on Sedimentation, ICWR, no. 970. Jackson, MS: US Department of Agriculture, 1963, p. 470.

[2] R. M. Sorensen, R. N. Weisman, and G. P. Lennon, "Control of erosion, inundation, and salinity intrusion caused by sea level rise," Barth MC, Titus JG (eds) Greenhouse effect and sea level rise. A challenge for this generation., vol. 214, p. 179, 1984.

[3] P. Youdeowei and T. Abam, "Local engineering practices of erosion control in the coastal areas of the Niger Delta," Environmental Geology, vol. 31, no. 3-4, pp. 231-235, 1997.

[4] H. Ardiny, S. Witwicki, and F. Mondada, "Construction automation with autonomous mobile robots: A review," in 3rd RSI International Conference on Robotics and Mechatronics (ICROM). IEEE, 2015, pp. 418-424.

[5] N. Napp and R. Nagpal, "Robotic construction of arbitrary shapes with amorphous materials," in 2014 IEEE International Conference on Robotics and Automation (ICRA). IEEE, 2014, pp. 438-444.

[6] M. Saboia, V. Thangavelu, W. Gosrich, and N. Napp, "Autonomous adaptive modification of unstructured environments," in Robotics: Science and Systems, 2011.

[7] S. J. Keating, J. C. Leland, L. Cai, and N. Oxman, "Toward sitespecific and self-sufficient robotic fabrication on architectural scales," Science Robotics, vol. 2, 2017.

[8] S. Jokic, P. Novikov, S. Maggs, D. Sadan, S. Jin, and C. Nan, "Robotic positioning device for three-dimensional printing," CoRR, 2014.

[9] I. Hurkxkens, C. Girot, and M. Hutter, "Robotic landscapes: Developing computational design tools towards autonomous terrain modeling," in Disciplines \& Disruption: Proceedings Catalog of the 37th Annual Conference of the Association for Computer Aided Design in Architecture (ACADIA), 2017, 2017, pp. 292-297.

[10] J. Flaherty, "Disney invents an adorable robot for making giant sand drawings," Wired, 2015.

[11] Federal Highway Administration, "Design and construction of driven pile foundations," 2016.

[12] J. Sklar, "Robots lay three times as many bricks as construction workers," MIT Technology Review, 2015.

[13] D. White, T. Finlay, M. Bolton, and G. Bearss, "Press-in piling: Ground vibration and noise during pile installation," in Deep Foundations 2002: An International Perspective on Theory, Design, Construction, and Performance, 2002, pp. 363-371.

[14] Störfix, "Rear-anchored sheet pile retaining wall near Dörfles-Esbach, Bavaria, Germany," 2005, [CC BY-SA 3.0; Accessed September 15, 2018]. [Online]. Available: https://commons.wikimedia.org/wiki/File: Spundwand.jpg

[15] F. Vincentz, "Nattbach vor der halde graf moltke am uferweg am nattbach in gladbeck," 2015, [CC BYSA 3.0; Accessed September 15, 2018]. [Online]. Available: https://commons.wikimedia.org/wiki/File:Gladbeck_-_Uferweg_ am_Nattbach_\%2B_Nattbach_\%2B_Halde_Graf_Moltke_01_ies.jpg

[16] US Environmental Protection Agency, "EPA and NSTAR begin to relocate power cables across harbor," 2010, [Public Domain; Accessed September 15, 2018]. [Online]. Available: https://commons.wikimedia.org/wiki/File:2001,_EPA_and_NSTAR_ begin_to_relocate_power_cables_across_harbor_(5202013182).jpg

[17] E. Guyassa, A. Frankl, A. Zenebe, J. Poesen, and J. Nyssen, "Effects of check dams on runoff characteristics along gully reaches, the case of Northern Ethiopia," Journal of Hydrology, vol. 545, pp. 299-309, 2017.

[18] X. Xiang-zhou, Z. Hong-wu, and Z. Ouyang, "Development of checkdam systems in gullies on the Loess Plateau, China," Environmental Science \& Policy, vol. 7, no. 2, pp. 79-86, 2004.

[19] L. Zeldovich, "The starfish terminator." Mechanical Engineering, vol. 140, pp. 36-41, 2018.

[20] Robots in the Service of the Environment, "The lionfish project: This invasive predator from the pacific is rapidly destroying our reefs." 2019, [Online; accessed February 21, 2019]. [Online]. Available: http://www.robotsise.org/the-guardian-solution/

[21] B. E. Cantrell and J. Holzman, Responsive landscapes: strategies for responsive technologies in landscape architecture. Routledge, 2015.

[22] G. Agoramoorthy and M. J. Hsu, "Small size, big potential: Check dams for sustainable development," Environment: Science and Policy for Sustainable Development, vol. 50, no. 4, pp. 22-35, 2008.
[23] F. K. Musgrave, C. E. Kolb, and R. S. Mace, "The synthesis and rendering of eroded fractal terrains," in ACM SIGGRAPH Computer Graphics, vol. 23, no. 3. ACM, 1989, pp. 41-50. 